\title{
Super typhoon disturbs organic contamination in agricultural soils
}

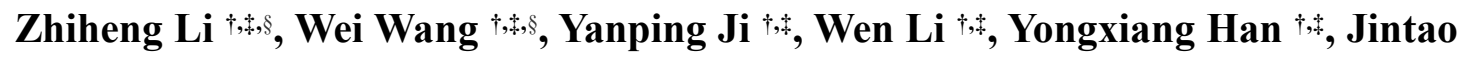

Xu', Yaqi Sheng ${ }^{\dagger, *}$, Zhou Shi ${ }^{*},+$, Lizhong Zhu ${ }^{*,+, *}$

${ }^{\dagger}$ College of Environmental and Resource Sciences, Zhejiang University, Hangzhou,

Zhejiang 310058, China

^Zhejiang Provincial Key Laboratory of Organic Pollution Process and Control,

Hangzhou, Zhejiang, 310058, China

${ }^{*}$ To whom correspondence may be addressed.

Tel: +8657188273733

Fax: +8657188273733

E-mail: zlz@zju.edu.cn

shizhou@zju.edu.cn

§These authors contributed equally: Zhiheng Li, Wei Wang 


\section{Captions}

Text S1. Sample pretreatment.

Text S2. Chemical analysis of PAHs, PAEs, OCPs and PCBs.

Text S3. Chemical analysis of products of PCBs.

Text S4. Chemical analysis of ${ }^{13} \mathrm{C}$ isotope.

Text S5. Environmental factor analysis during the sampling and typhoon period.

Table S1. The properties and structures of tested organic contaminants.

Table S2. The recoveries, limits of detection and limits of quantitation for the analysis of PAHs, PAEs, OCPs and PCBs.

Table S3. The recoveries, limits of detection and limits of quantitation for the analysis of the products of PCBs.

Table S4. The concentrations of organic contaminants in $0-20 \mathrm{~cm}$ soils of the Yangtze River Delta before the typhoon Lekima.

Table S5. The concentrations of organic contaminants in $0-20 \mathrm{~cm}$ soils of the Yangtze River Delta after the typhoon Lekima.

Table S6. The influence of environmental factors on the variation of the concentrations of organic contaminants in the YRD.

Figure S1. The decrease of the chlorinated-organics in soils after the typhoon as a function of the number of chlorine substituents.

Figure S2. The major drivers of the disturbance of soils organic contaminants in YRD during the typhoon period (a-d) and the sampling period (e-h).

Figure S3. The vertical distribution of ${ }^{13} \mathrm{C}$ in agricultural soils from the Yangtze River 
Delta before and after the typhoon Lekima.

Figure S4. The vertical distribution of total PAHs (a) and PAH monomers (b) in agricultural soils from the Yangtze River Delta before and after the typhoon Lekima.

Figure S5. The relationship between $R I$ and $\lg K_{\text {ow }}$.

Figure S6. The distribution of total PCBs in agricultural soil profiles from the Yangtze River Delta before and after the typhoon.

Figure S7. The transformation products of PCBs in $0-20 \mathrm{~cm}$ soils from the Yangtze River Delta before and after the typhoon.

Figure S8. The vertical distribution of total OCPs in agricultural soil profiles from the Yangtze River Delta before and after the typhoon.

Figure S9. The distribution of total rainfalls in the YRD during the typhoon. (a) The effects of hourly rainfalls on the soil erosion during the typhoon. (b) The effects of hourly rainfalls on the soil organic contamination during the typhoon. (c)

Figure S10. The vertical spatial distribution of organic contaminants in 0-5 cm and 10$20 \mathrm{~cm}$ soil layers from the Yangtze River Delta during the typhoon. 


\section{Text S1. Sample pretreatment}

The concentration variation and distribution characteristics of PAHs, PCBs, the metabolites of PCBs and the stable carbon isotopes $\left({ }^{13} \mathrm{C}\right)$ in agricultural soils were all determined. Surrogate standards (200 ng tetrachloro-m-xylene and pyrene-d10) were added to 10 -g soil samples, followed by extraction with $20 \mathrm{~mL}$ hexane/acetone $(1: 1$, $\mathrm{v} / \mathrm{v}$ ) in a microwave digestion system (MARS Xpress, USA). The temperature for digestion was initially set $25^{\circ} \mathrm{C}$, increased to $110^{\circ} \mathrm{C}$ at a rate of $10^{\circ} \mathrm{C} / \mathrm{min}$, held for 10 min and then allowed to cool down to room temperature. The extract was then filtered with a sand core funnel $(2-5 \mu \mathrm{m})$ and concentrated with the use of rotary evaporator at $30^{\circ} \mathrm{C}$. The concentrates were further cleaned up with a glass chromatographic column containing $12 \mathrm{~g}$ soaked neutral aluminum oxide, $12 \mathrm{~g}$ soaked silica gel and $1 \mathrm{~g}$ anhydrous sodium sulfate (which had been baked for $6 \mathrm{~h}$ at $600^{\circ} \mathrm{C}$ ). The extract was eluted with $50 \mathrm{~mL}$ hexane/dichloromethane $(1: 1, \mathrm{v} / \mathrm{v})$. The eluent containing the target compounds was condensed to $1-2 \mathrm{~mL}$ with a rotary evaporator and then re-dissolved to hexane and re-evaporated to $1 \mathrm{~mL}$. Internal standards were added to each concentrated sample prior to storage in $2-\mathrm{mL}$ glass vials at $4^{\circ} \mathrm{C}$ in preparation. The pretreated samples were further subjected to specific quantification of PAHs, PCBs, PCB metabolites, and ${ }^{13} \mathrm{C}$ isotope for chemical analysis. 


\section{Text S2. Chemical analysis of PAHs, PAEs, OCPs and PCBs.}

The quantification of PAHs, PAEs, OCPs and PCBs was performed using a gas chromatograph-mass spectrometer (GC-MS, Agilent ${ }^{\circledR}$ 7890B-5977B). The MS detector was initially operated in scanning mode to obtain the retention time of each compound for qualitative analysis, and then operated in electron impact (EI: $70 \mathrm{eV}$ ) of selected ion monitoring (SIM) mode for quantitative analysis. The GC was equipped with a DB-5MS column $(30 \mathrm{~m} \times 0.25 \mathrm{~mm}$ i.d. $\times 0.25 \mathrm{~mm})$. Helium was used as the carrier gas with a constant flow rate of $1.0 \mathrm{~mL} / \mathrm{min}$ and a constant head pressure of 30 $\mathrm{kPa}$. The injection mode was splitless and the injection volume was $1 \mathrm{~mL}$. The oven temperature was set at $60^{\circ} \mathrm{C}$ for $1 \mathrm{~min}$, increased to $270^{\circ} \mathrm{C}$ at a rate of $5^{\circ} \mathrm{C} / \mathrm{min}$ and held for $2 \mathrm{~min}$, and then increased to $290^{\circ} \mathrm{C}$ at a rate of $3^{\circ} \mathrm{C} / \mathrm{min}$ and held for $1 \mathrm{~min}$, increased to the final temperature of $305^{\circ} \mathrm{C}$ at a rate of $10^{\circ} \mathrm{C} / \mathrm{min}$ and held for $12 \mathrm{~min}$. The temperatures of the injector, ion source and quadrupole were 290,230 and $150{ }^{\circ} \mathrm{C}$, respectively. 


\section{Text S3. Chemical analysis of products of PCBs.}

PCBs of different numbers of chlorine substituents were selected as representative compounds to evaluate the effects of typhoon on the soil contamination of chlorinated organics. Thus, we selected CB28, CB61, CB101, CB118, CB153, representing PCBs of $3,4,5,6,6,6$, and 7 chlorine substituents. In the case of PCB61, 4'-MeO-CB61 and 4'-OH-CB61 was selected as typical metabolites to explore the influence mechanism. Half of the extract (100 $\mu \mathrm{L}$ in hexane) was used for the analysis of 4'-MeO-CB61 by GC-MS with an electron ionization (EI) ion source. A DB-5MS (J\&W Scientific, Folsom, CA, USA) capillary column $(30 \mathrm{~m} \times 0.25 \mathrm{~mm}$ i.d. $\times 0.25 \mathrm{~mm})$ was applied to separate the target compounds. Helium was used as the carrier gas at a constant flow rate of $1 \mathrm{~mL} / \mathrm{min}$. The oven was initially set to $90^{\circ} \mathrm{C}$ and increased to $210^{\circ} \mathrm{C}$ at a rate of $20^{\circ} \mathrm{C} / \mathrm{min}$, then increased to $300^{\circ} \mathrm{C}$ at a rate of $6^{\circ} \mathrm{C} / \mathrm{min}$. The selected ion monitoring (SIM) mode was applied for quantitative determination. The $\mathrm{m} / \mathrm{z}$ of monitoring ions was 322.0 and 278.9 for 4'-MeO-CB61.

The other half of the extract was evaporated to dryness and dissolved in acetonitrile liquid chromatograph-tandem mass spectrometer (LC-MS/MS, Agilent ${ }^{\circledR 1260-6460) . ~}$ The compounds were separated on a C18 column $(100 \mathrm{~mm} \times 2.1 \mathrm{~mm}, 2.2 \mu \mathrm{m}$ particle size; Thermo Fisher Scientific, Waltham, MA, USA). The mobile phase consisting of acetonitrile and water was used with a gradient elution from 60:40 to 75:25 in 20 min at a flowrate of $0.3 \mathrm{~mL} / \mathrm{min}$. The mass spectrometric detection was performed using an electrospray ionization (ESI) source in negative ion multiple-reaction monitoring (MRM) mode. The MRM transition used for quantification and qualitative analysis of 4'-OH-CB61 was $m / z \quad 342.8 \rightarrow 306.8$ and $306.8 \rightarrow 35.0$, respectively. The recoveries, 
limits of detection and limits of quantitation of 4'-MeO-CB61 and 4'-OH-CB61 were summarized in Table S2. The recoveries were determined using the same method for 4'-MeO-CB61 and 4'-OH-CB61 analysis and were in the range of 89.4-91.2\%. The instrument detection limits and method detection limits were in the range of $0.01-0.04$ $\mathrm{ng} / \mathrm{mL}$ and $0.16-0.26 \mu \mathrm{g} / \mathrm{kg}$, respectively. The limits of quantification were in the range of $0.52-0.88 \mu \mathrm{g} / \mathrm{kg}$.

\section{Text S4. Chemical analysis of ${ }^{13} \mathrm{C}$ isotope}

The ${ }^{13} \mathrm{C}$ isotope contents were measured by a gas chromatography-isotope ratio mass spectrometry (GC-IRMS, Thermo Fisher Trace GC/Delta V Advantage). The $\delta^{13} \mathrm{C}$ is defined as follows:

$\delta(\%)=\left(\left(R_{\text {standard }} / R_{\text {standard }}\right)-1\right) \times 1000$

where $\delta$ is the isotopic composition, $R_{\text {sample }}$ is the ${ }^{13} \mathrm{C} /{ }^{12} \mathrm{C}$ ratio in a sample for $\delta^{13} \mathrm{C}$ and $R_{\text {standard }}$ is the ${ }^{13} \mathrm{C} /{ }^{12} \mathrm{C}$ ratio of the international PeeDee Belemnite standard for $\delta^{13} \mathrm{C}$. Contents of $\delta^{13} \mathrm{C}$ were performed using a Thermo Quest Finnigan Delta Plus XL IRMS coupled to an Agilent 6890 GC via a Thermo Quest Finnigan GC Combustion III interface. The reported isotopic results, expressed in the per mil (\%o) deviation of the isotope ratio from the standards Vienna Peedee belemnite (PDB) and Vienna standard mean ocean water for carbon, represent the arithmetic means of triplicate analyses. The accuracies of the sample measurements were estimated as the standard deviation between the real and the calculated values of standards and were all within $0.6 \%$ for $\delta^{13} \mathrm{C}$. The total errors of these analyses were reported as the largest uncertainty associated with either precision or accuracy for each sample. 


\section{Text S5. Environmental factor analysis during the sampling and typhoon period}

To determine if the fluctuations in soil organic contaminants driven by the typhoon could be explained by environmental variables, the mean precipitation (AP, mm/h), mean air temperature (AT, $\left.{ }^{\circ} \mathrm{F}\right)$, mean air humidity $(\mathrm{AH}, \%)$, mean wind speed (WS, $\mathrm{m} / \mathrm{s})$, mean concentration of $\mathrm{PM}_{2.5}\left(\mathrm{PM}_{2.5}, \mu \mathrm{g} / \mathrm{m}^{3}\right)$, mean concentration of $\mathrm{PM}_{10}\left(\mathrm{PM}_{10}\right.$, $\mu \mathrm{g} / \mathrm{m}^{3}$ ), mean soil temperature $\left(\mathrm{ST},{ }^{\circ} \mathrm{F}\right)$, mean soil surface temperature $\left(\mathrm{SST},{ }^{\circ} \mathrm{F}\right)$ and mean 0-5 cm soil moisture (SM, \%) data were obtained from the WorldClim database (http://www.worldclim.org). The data of mean vegetation coverage (VG, \%) and mean population density (PD, people per unit area) were collected from the China annual Vegetation Index (NDVI) spatial distribution data set and China Statistical Yearbook. The content of soil organic matter (SOM, \%) was determined using an Elementary Vario EL III elemental analyzer (Hanau, Germany). These environmental variables could directly or indirectly influence the distribution of PAHs, PAEs, OCPs and PCBs in soils in the YRD during the typhoon. A Random Forest model was used to identify the most important driver of environmental variables among the 12 variables. The response variables are bootstrap resampling to generate untrimmed decision trees (1000 trees in our study). The best split of each tree is assessed using randomly selecting subsets (1/3 of all variables). We divided the top eight indicator variables induced by the typhoon obtained from the Random Forest model into latent variables. The relationships between environmental factors, PAHs, PAEs, OCPs and PCBs were evaluated by Partial Least Squares Path Modeling (PLSPM), a useful statistical method for revealing cause and effect relationships among observed and latent variables. In structural model, we considered the following potential path and hypothesized that the typhoon has a direct and indirect effect on soil organic contaminants through its effects on environmental factors. The estimates of path coefficients and the coefficients of 
determination $\left(\mathrm{R}^{2}\right)$ in our path model were validated by $\mathrm{R}$ (v. 3.4.0) with the PLSPM package. 
Table S1. The properties and structures of tested organic contaminants

\begin{tabular}{|c|c|c|c|}
\hline Compounds & $\lg K_{\text {ow }}$ & Structure & Formula \\
\hline \multicolumn{4}{|l|}{ PAHs } \\
\hline NAP & 3.5 & & $\mathrm{C}_{10} \mathrm{H}_{8}$ \\
\hline ANY & 3.9 & & $\mathrm{C}_{12} \mathrm{H}_{8}$ \\
\hline ANA & 3.9 & & $\mathrm{C}_{12} \mathrm{H}_{10}$ \\
\hline FLU & 4.2 & & $\mathrm{C}_{13} \mathrm{H}_{10}$ \\
\hline PHE & 4.5 & & $\mathrm{C}_{14} \mathrm{H}_{10}$ \\
\hline ANT & 4.5 & & $\mathrm{C}_{14} \mathrm{H}_{10}$ \\
\hline FLT & 5.2 & & $\mathrm{C}_{16} \mathrm{H}_{10}$ \\
\hline PYR & 4.9 & & $\mathrm{C}_{16} \mathrm{H}_{10}$ \\
\hline CHR & 5.8 & & $\mathrm{C}_{16} \mathrm{H}_{10}$ \\
\hline $\mathrm{BaA}$ & 5.8 & & $\mathrm{C}_{18} \mathrm{H}_{12}$ \\
\hline BbFA & 5.8 & & $\mathrm{C}_{22} \mathrm{H}_{12}$ \\
\hline $\mathrm{BkFA}$ & 6.1 & & $\mathrm{C}_{22} \mathrm{H}_{12}$ \\
\hline $\mathrm{BaP}$ & 6.1 & & $\mathrm{C}_{20} \mathrm{H}_{12}$ \\
\hline $\mathrm{DbA}$ & 6.1 & & $\mathrm{C}_{22} \mathrm{H}_{14}$ \\
\hline IND & 6.7 & & $\mathrm{C}_{12} \mathrm{H}_{12}$ \\
\hline
\end{tabular}




\begin{tabular}{|c|c|c|}
\hline BghiP & 6.7 & $\mathrm{C}_{22} \mathrm{H}_{12}$ \\
\hline \multicolumn{3}{|l|}{ PAEs } \\
\hline DMP & 1.6 & $\mathrm{C}_{10} \mathrm{H}_{10} \mathrm{O}_{4}$ \\
\hline DEP & 2.4 & $\mathrm{C}_{12} \mathrm{H}_{14} \mathrm{O}_{4}$ \\
\hline DnBP & 4.5 & $\mathrm{C}_{16} \mathrm{H}_{22} \mathrm{O}_{4}$ \\
\hline BBP & 4.7 & $\mathrm{C}_{19} \mathrm{H}_{20} \mathrm{O}_{4}$ \\
\hline DEHP & 7.6 & $\mathrm{C}_{24} \mathrm{H}_{38} \mathrm{O}_{4}$ \\
\hline DnOP & 8.1 & $\mathrm{C}_{24} \mathrm{H}_{38} \mathrm{O}_{4}$ \\
\hline \multicolumn{3}{|l|}{ OCPs } \\
\hline$\alpha-\mathrm{HCH}$ & 3.7 & $\mathrm{C}_{6} \mathrm{C}_{16}$ \\
\hline$\beta-\mathrm{HCH}$ & 3.7 & $\mathrm{C}_{6} \mathrm{Cl}_{6}$ \\
\hline$\gamma-\mathrm{HCH}$ & 3.7 & $\mathrm{C}_{6} \mathrm{Cl}_{6}$ \\
\hline$\delta-\mathrm{HCH}$ & 3.7 & $\mathrm{C}_{6} \mathrm{Cl}_{6}$ \\
\hline 4,4'-DDE & 6.5 & $\mathrm{C}_{14} \mathrm{H}_{8} \mathrm{Cl}_{4}$ \\
\hline 4,4'-DDD & 6.8 & $\mathrm{C}_{14} \mathrm{H}_{10} \mathrm{Cl}_{4}$ \\
\hline $4,4^{\prime}-\mathrm{DDT}$ & 6.9 & $\mathrm{C}_{14} \mathrm{H}_{9} \mathrm{Cl}_{5}$ \\
\hline
\end{tabular}




CB28

Transformation products

of PCBs

4'-MeO-CB61

4.2

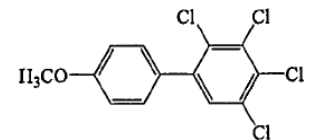

$\mathrm{C}_{13} \mathrm{H}_{8} \mathrm{OCl}_{4}$

4'-OH-CB61

6.4

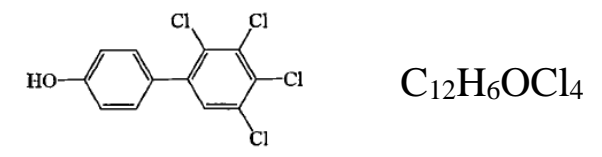


Table S2. The recoveries, limits of detection and limits of quantitation for the analysis of PAHs, PAEs, OCPs and PCBs

\begin{tabular}{|c|c|c|c|c|c|}
\hline \multicolumn{2}{|c|}{ Compounds } & \multirow{2}{*}{$\begin{array}{c}\text { Recovery, \% } \\
82.6 \pm 8.1\end{array}$} & \multirow{2}{*}{$\begin{array}{c}\mathrm{LOD} 1, \mathrm{ng} / \mathrm{ml} \\
0.07\end{array}$} & \multirow{2}{*}{$\begin{array}{c}\text { LOD2, ng/g } \\
0.09\end{array}$} & \multirow{2}{*}{$\begin{array}{c}\mathrm{LOQ}, \mathrm{ng} / \mathrm{g} \\
0.28\end{array}$} \\
\hline \multirow{16}{*}{ PAHs } & NAP & & & & \\
\hline & ANY & $89.6 \pm 4.7$ & 0.03 & 0.06 & 0.20 \\
\hline & ANA & $93.5 \pm 3.1$ & 0.02 & 0.09 & 0.35 \\
\hline & FLU & $98.8 \pm 9.4$ & 0.02 & 0.03 & 0.10 \\
\hline & PHE & $94.6 \pm 8.4$ & 0.04 & 0.06 & 0.19 \\
\hline & ANT & $88.4 \pm 5.6$ & 0.01 & 0.03 & 0.11 \\
\hline & FLT & $93.0 \pm 1.2$ & 0.04 & 0.05 & 0.15 \\
\hline & PYR & $99.9 \pm 10.2$ & 0.03 & 0.06 & 0.20 \\
\hline & $\mathrm{BaA}$ & $96.8 \pm 5.7$ & 0.02 & 0.03 & 0.11 \\
\hline & CHR & $89.4 \pm 10.5$ & 0.03 & 0.06 & 0.15 \\
\hline & $\mathrm{BbFA}$ & $97.5 \pm 2.9$ & 0.02 & 0.05 & 0.16 \\
\hline & BkFA & $85.4 \pm 7.7$ & 0.01 & 0.08 & 0.25 \\
\hline & $\mathrm{BaP}$ & $93.4 \pm 6.4$ & 0.05 & 0.07 & 0.22 \\
\hline & IND & $83.4 \pm 2.2$ & 0.09 & 0.12 & 0.38 \\
\hline & DBA & $90.7 \pm 4.8$ & 0.10 & 0.12 & 0.44 \\
\hline & BghiP & $80.8 \pm 7.2$ & 0.14 & 0.19 & 0.58 \\
\hline \multirow{6}{*}{ PAEs } & DMP & $83.4 \pm 0.4$ & 0.16 & 0.20 & 0.50 \\
\hline & DEP & $99.7 \pm 13.4$ & 0.14 & 0.18 & 0.50 \\
\hline & DnBP & $98.6 \pm 3.4$ & 0.02 & 0.04 & 0.10 \\
\hline & $\mathrm{BBP}$ & $101.4 \pm 8.9$ & 0.03 & 0.06 & 0.10 \\
\hline & DEHP & $97.2 \pm 5.9$ & 0.03 & 0.07 & 0.10 \\
\hline & DnOP & $92.4 \pm 5.7$ & 0.06 & 0.10 & 0.20 \\
\hline \multirow{7}{*}{ OCPs } & $\alpha-\mathrm{HCH}$ & $97.1 \pm 9.4$ & 0.07 & 0.12 & 0.22 \\
\hline & $\beta-\mathrm{HCH}$ & $95.4 \pm 7.7$ & 0.08 & 0.11 & 0.25 \\
\hline & $\gamma-\mathrm{HCH}$ & $93.8 \pm 2.7$ & 0.03 & 0.05 & 0.11 \\
\hline & $\delta-\mathrm{HCH}$ & $96.4 \pm 6.9$ & 0.02 & 0.03 & 0.05 \\
\hline & $4,4^{\prime}-\mathrm{DDE}$ & $94.6 \pm 8.4$ & 0.06 & 0.09 & 0.19 \\
\hline & 4,4'-DDD & $98.4 \pm 5.0$ & 0.04 & 0.06 & 0.15 \\
\hline & 4,4'-DDT & $97.9 \pm 1.2$ & 0.06 & 0.10 & 0.20 \\
\hline \multirow{2}{*}{ PCBs } & CB-28 & $83.4 \pm 0.4$ & 0.04 & 0.06 & 0.22 \\
\hline & CB-61 & $99.7 \pm 13.4$ & 0.01 & 0.03 & 0.10 \\
\hline
\end{tabular}




$\begin{array}{lclll}\text { CB-101 } & 98.6 \pm 3.4 & 0.08 & 0.10 & 0.32 \\ \text { CB-118 } & 101.4 \pm 8.9 & 0.03 & 0.08 & 0.25 \\ \text { CB-138 } & 97.2 \pm 5.9 & 0.04 & 0.08 & 0.26 \\ \text { CB-153 } & 85.4 \pm 4.2 & 0.02 & 0.12 & 0.39 \\ \text { CB-180 } & 92.4 \pm 5.7 & 0.01 & 0.05 & 0.16\end{array}$

(1) Recovery $(\%)=($ Concentration of pre-spiked sample - Concentration of no-spiked sample) / Concentration of standard sample, where the pre-spiked sample represents the soil sample spiked before the pretreatment, and the no-spike sample represents the soil sample without spike. Recovery was determined by analysis of soil samples spiked with PAHs and PCBs at $5 \mathrm{ng} / \mathrm{g}$. The concentrations of soil samples were determined by the standard addition method. The standard soil sample was GSS-3 (GBW07403)。 (2) LOD1 is the limits of detection (LOD) in the GC-MS method from analysis of 1 $\mathrm{ng} / \mathrm{mL}$ standards and blanks, which is estimated as the concentration when the signalto-noise ratio equals 3 . The noise is determined by 3 times of the average peak area of 6 blank samples, and the signal is determined by the average peak area of triplicate 1 $\mathrm{ng} / \mathrm{mL}$ standard solution of PAHs and PCBs.

(3) LOD2 is the LOD in the pretreatment and GC-MS method for analysis of PAHs and PCBs in the standard soil samples, which is also estimated as the concentration when the signal-to-noise ratio equals 3 . The noise is determined by the average peak area of triplicate blank soil samples that were concentrated by the pretreatment and then analyzed by GC-MS. The signal is determined by the average peak area of triplicate 1 $\mathrm{ng} / \mathrm{g}$ standard soil samples analyzed using GC-MS analysis.

(4) LOQ is the limits of quantitation in the pretreatment and GC-MS method for analysis of PAHs and PCBs in the treated soil samples, which is estimated as the concentration when the signal-to-noise ratio equals 10 . The determination of noise and signal is the same as LOD2. 
Table S3. The recoveries, limits of detection and limits of quantitation for the analysis of the products of PCBs

\begin{tabular}{ccccc}
\hline Compounds & Recovery, \% & LOD1, ng/mL & LOD2, ng/g & LOQ, ng/g \\
\hline 4'-MeO-CB61 & $91.2 \pm 3.9$ & 0.02 & 0.16 & 0.52 \\
4'-OH-CB61 & $89.4 \pm 2.7$ & 0.04 & 0.26 & 0.88 \\
\hline
\end{tabular}

(1) Recovery $(\%)=($ Concentration of pre-spiked sample - Concentration of no-spiked sample) / Concentration of standard sample, where the pre-spiked sample represents the standard soil sample spiked before the pretreatment, and the no-spike sample represents the standard soil sample without spike. Recovery was determined by analysis of soil samples spiked with 4'-MeO-CB61 and 4'-OH-CB61 at $10 \mathrm{ng} / \mathrm{g}$. The concentrations of soil samples were determined by the standard addition method. The standard soil sample was GSS-3 (GBW07403)。

(2) LOD1 of 4'-MeO-CB61 is the LOD in the GC-MS method from analysis of $1 \mathrm{ng} / \mathrm{g}$ standards and blanks, which is estimated as the concentration when the signal-to-noise ratio equals 3. The noise is determined by 3 times of the average peak area of 6 blank samples, and the signal is determined by the average peak area of triplicate $1 \mathrm{ng} / \mathrm{mL}$ standard solutions of PAHs and PCBs.

(3) LOD1 of 4'-OH-CB61 is the LOD in the LC-MS/MS method from analysis of 2 $\mathrm{ng} / \mathrm{g}$ standards solutions and blanks, which is estimated as the concentration when the signal-to-noise ratio equals 3 . The noise is determined by 3 times of the average peak area of 6 blank samples, and the signal is determined by the average peak area of triplicate $2 \mathrm{ng} / \mathrm{mL}$ standard solutions of PAHs and PCBs.

(4) LOD2 of 4'-MeO-CB61 is the LOD in the pretreatment and GC-MS method for analysis of 4'-MeO-CB61 in the standard soil samples, which is also estimated as the concentration when the signal-to-noise ratio equals 3 . The noise is determined by the average peak area of triplicate blank soil samples that were concentrated by the pretreatment and then analyzed by GC-MS. The signal is determined by the average peak area of triplicate $1 \mathrm{ng} / \mathrm{g}$ standard soil samples analyzed using GC-MS analysis.

(5) LOD2 of 4'-OH-CB61 is the LOD in the pretreatment and LC-MS/MS method for 
analysis of 4'-OH-CB61 in the standard soil samples, which is also estimated as the concentration when the signal-to-noise ratio equals 3 . The noise is determined by the average peak area of triplicate blank soil samples that were concentrated by the pretreatment and then analyzed by the LC-MS/MS. The signal is determined by the average peak area of triplicate $2 \mathrm{ng} / \mathrm{g}$ standard soil samples analyzed using LC-MS/MS analysis.

(6) LOQ is the limits of quantitation of the pretreatment and GC-MS method for analysis of 4'-MeO-CB61 and 4'-OH-CB61 in the treated soil samples, which is estimated as the concentration when the signal-to-noise ratio equals 10 . The determination of noise and signal is the same as LOD2 of 4'-MeO-CB61 and 4'-OHCB61, respectively. 
Table S4. The concentrations of organic contaminants in $0-20 \mathrm{~cm}$ soils of the Yangtze River Delta before the typhoon Lekima, $\mu \mathrm{g} / \mathrm{kg}$

\begin{tabular}{|c|c|c|c|c|}
\hline Compounds & $\begin{array}{l}\text { Detected frequency } \\
\qquad(\%)\end{array}$ & $\begin{array}{c}\text { Min } \\
(\mu \mathrm{g} / \mathrm{kg})\end{array}$ & $\begin{array}{c}\operatorname{Max} \\
(\mu \mathrm{g} / \mathrm{kg})\end{array}$ & $\begin{array}{c}\text { Mean } \pm \text { STD } \\
(\mu \mathrm{g} / \mathrm{kg})\end{array}$ \\
\hline NAP & 83.05 & $<0.28$ & 48.32 & $3.31 \pm 0.27$ \\
\hline ANY & 64.05 & $<0.20$ & 2131.23 & $18.41 \pm 1.14$ \\
\hline ANA & 59.55 & $<0.35$ & 200.76 & $12.08 \pm 4.63$ \\
\hline FLU & 76.40 & $<0.10$ & 1790.51 & $13.02 \pm 2.64$ \\
\hline PHE & 65.17 & $<0.19$ & 1956.03 & $41.92 \pm 10.24$ \\
\hline ANT & 49.44 & $<0.11$ & 2008.61 & $16.34 \pm 2.037$ \\
\hline FLT & 83.15 & $<0.15$ & 5440.07 & $79.11 \pm 10.51$ \\
\hline PYR & 83.15 & $<0.20$ & 6533.12 & $90.98 \pm 15.04$ \\
\hline $\mathrm{BaA}$ & 79.78 & $<0.15$ & 2263.20 & $86.81 \pm 30.17$ \\
\hline CHR & 30.34 & $<0.11$ & 400.70 & $56.22 \pm 10.42$ \\
\hline $\mathrm{BbFA}$ & 77.52 & $<0.16$ & 962.43 & $45.11 \pm 20.17$ \\
\hline $\mathrm{BkFA}$ & 55.06 & $<0.25$ & 4836.91 & $44.12 \pm 30.23$ \\
\hline $\mathrm{BaP}$ & 68.54 & $<0.22$ & 5066.05 & $43.34 \pm 12.86$ \\
\hline IND & 20.35 & $<0.38$ & 143.40 & $14.36 \pm 4.37$ \\
\hline $\mathrm{DBA}$ & 69.91 & $<0.44$ & 655.11 & $12.52 \pm 2.42$ \\
\hline BghiP & 15.25 & $<0.58$ & 20.15 & $1.52 \pm 0.25$ \\
\hline $\mathrm{DMP}$ & 86.17 & $<0.50$ & 2.18 & $0.43 \pm 0.04$ \\
\hline DEP & 70.82 & $<0.50$ & 4.14 & $0.42 \pm 0.11$ \\
\hline DnBP & 98.74 & $<0.10$ & 69.48 & $6.12 \pm 1.08$ \\
\hline BBP & 29.35 & $<0.10$ & 96.33 & $0.86 \pm 0.29$ \\
\hline DEHP & 99.57 & $<0.10$ & 1510.15 & $183.43 \pm 15.42$ \\
\hline DnOP & 89.85 & $<0.20$ & 74.86 & $6.97 \pm 5.74$ \\
\hline$\alpha-\mathrm{HCH}$ & 30.34 & $<0.22$ & 67.78 & $6.44 \pm 1.16$ \\
\hline$\beta-\mathrm{HCH}$ & 100 & 0.91 & 7.23 & $3.91 \pm 1.04$ \\
\hline$\gamma-\mathrm{HCH}$ & 100 & 0.82 & 7.06 & $3.56 \pm 0.54$ \\
\hline$\delta-\mathrm{HCH}$ & 100 & 0.97 & 7.24 & $4.35 \pm 0.78$ \\
\hline 4,4'-DDD & 19.10 & $<0.19$ & 51.92 & $4.21 \pm 1.04$ \\
\hline 4,4'-DDE & 70.03 & $<0.15$ & 755.03 & $20.01 \pm 8.55$ \\
\hline 4,4'-DDT & 32.58 & $<0.20$ & 657.32 & $10.22 \pm 2.92$ \\
\hline CB-28 & 96.63 & $<0.22$ & 210.43 & $38.28 \pm 24.38$ \\
\hline
\end{tabular}




\begin{tabular}{ccccc} 
CB-61 & 76.40 & $<0.10$ & 178.82 & $12.37 \pm 5.35$ \\
CB-101 & 46.07 & $<0.32$ & 59.06 & $5.91 \pm 2.03$ \\
CB-118 & 15.73 & $<0.25$ & 163.63 & $5.75 \pm 3.64$ \\
CB-138 & 39.33 & $<0.26$ & 34.43 & $3.12 \pm 1.44$ \\
CB-153 & 26.97 & $<0.39$ & 145.12 & $5.68 \pm 4.38$ \\
CB-180 & 41.57 & $<0.16$ & 181.64 & $7.98 \pm 6.55$ \\
\hline
\end{tabular}

Detection rate is the ratio of the number of samples ( $>$ limits of quantitation) to the total number of samples (228).

Max, Min and Mean is referred to the maximum, minimum and average concentrations of the tested compounds in the 228 samples, respectively.

STD is referred to the standard deviation of concentration of compounds with triplicate samples. 
Table S5. The concentrations of organic contaminants in $0-20 \mathrm{~cm}$ soils of the Yangtze River Delta after the typhoon Lekima, $\mu \mathrm{g} / \mathrm{kg}$

\begin{tabular}{|c|c|c|c|c|}
\hline Compounds & $\begin{array}{c}\text { Detected frequency } \\
\qquad(\%)\end{array}$ & $\begin{array}{c}\text { Min } \\
(\mu \mathrm{g} / \mathrm{kg})\end{array}$ & $\begin{array}{c}\operatorname{Max} \\
(\mu \mathrm{g} / \mathrm{kg})\end{array}$ & $\begin{array}{c}\text { Mean } \pm \text { STD } \\
(\mu \mathrm{g} / \mathrm{kg})\end{array}$ \\
\hline NAP & 92.59 & $<0.28$ & 85.75 & $5.84 \pm 1.01$ \\
\hline ANY & 86.11 & $<0.20$ & 1831.07 & $30.25 \pm 11.53$ \\
\hline ANA & 88.43 & $<0.35$ & 266.73 & $22.38 \pm 4.32$ \\
\hline FLU & 100 & $<0.10$ & 1814.50 & $22.73 \pm 5.45$ \\
\hline PHE & 98.15 & $<0.19$ & 1560.00 & $75.41 \pm 38.74$ \\
\hline ANT & 100 & 1.84 & 2093.90 & $27.27 \pm 12.42$ \\
\hline FLT & 100 & 0.18 & 1357.82 & $121.72 \pm 15.33$ \\
\hline PYR & 99.54 & $<0.20$ & 6695.04 & $134.54 \pm 22.72$ \\
\hline CHR & 87.50 & $<0.15$ & 2879.52 & $131.51 \pm 13.25$ \\
\hline $\mathrm{BaA}$ & 93.06 & $<0.11$ & 3428.07 & $104.47 \pm 32.28$ \\
\hline $\mathrm{BbFA}$ & 46.76 & $<0.16$ & 4811.05 & $64.56 \pm 20.13$ \\
\hline $\mathrm{BkFA}$ & 76.39 & $<0.25$ & 7017.19 & $63.66 \pm 13.37$ \\
\hline $\mathrm{BaP}$ & 83.80 & $<0.22$ & 7493.05 & $63.12 \pm 22.71$ \\
\hline IND & 71.76 & $<0.38$ & 172.07 & $17.26 \pm 4.17$ \\
\hline DBA & 71.76 & $<0.44$ & 770.93 & $14.51 \pm 5.44$ \\
\hline BghiP & 74.54 & $<0.58$ & 113.43 & $2.18 \pm 1.19$ \\
\hline DMP & 86.57 & $<0.50$ & 3.89 & $0.53 \pm 0.12$ \\
\hline DEP & 75.93 & $<0.50$ & 4.31 & $0.43 \pm 0.04$ \\
\hline DnBP & 98.15 & $<0.10$ & 72.58 & $6.43 \pm 1.47$ \\
\hline BBP & 28.70 & $<0.10$ & 107.81 & $0.97 \pm 0.22$ \\
\hline DEHP & 99.57 & $<0.10$ & 1595.74 & $192.52 \pm 21.49$ \\
\hline DnOP & 99.07 & $<0.20$ & 75.22 & $7.11 \pm 3.36$ \\
\hline$\alpha-\mathrm{HCH}$ & 76.85 & $<0.22$ & 22.84 & $2.21 \pm 0.09$ \\
\hline$\beta-\mathrm{HCH}$ & 100 & 0.28 & 2.95 & $1.21 \pm 0.14$ \\
\hline$\gamma-\mathrm{HCH}$ & 100 & 0.23 & 2.42 & $1.00 \pm 0.23$ \\
\hline$\delta-\mathrm{HCH}$ & 100 & 0.23 & 2.27 & $1.06 \pm 0.02$ \\
\hline $4,4^{\prime}-\mathrm{DDD}$ & 31.02 & $<0.19$ & 26.20 & $2.15 \pm 0.04$ \\
\hline 4,4'-DDE & 85.65 & $<0.15$ & 407.41 & $10.58 \pm 1.35$ \\
\hline 4,4'-DDT & 48.15 & $<0.20$ & 298.89 & $4.58 \pm 0.79$ \\
\hline CB-28 & 80.56 & $<0.22$ & 107.06 & $19.11 \pm 0.79$ \\
\hline
\end{tabular}




\begin{tabular}{ccccc} 
CB-61 & 66.67 & $<0.10$ & 63.29 & $4.33 \pm 0.43$ \\
CB-101 & 60.19 & $<0.32$ & 26.30 & $1.63 \pm 0.21$ \\
CB-118 & 29.17 & $<0.25$ & 42.07 & $1.44 \pm 0.09$ \\
CB-138 & 31.48 & $<0.26$ & 9.78 & $0.87 \pm 0.15$ \\
CB-153 & 45.37 & $<0.39$ & 31.73 & $1.27 \pm 0.21$ \\
CB-180 & 50.93 & $<0.16$ & 35.19 & $1.51 \pm 0.23$ \\
\hline
\end{tabular}

Detection frequency is the ratio of the number of samples ( $>$ limits of quantitation) to the total number of samples (228).

Max, Min and Mean is referred to the maximum, minimum and average concentrations of the tested compounds in the 228 samples, respectively.

STD is referred to the standard deviation of concentration of compounds with triplicate samples. 
Table S6. The influence of environmental factors on the variation of the concentrations of organic contaminants in the YRD

\begin{tabular}{ccccc}
\hline Category & Factors & Abbreviation & Unit & Source \\
\hline \multirow{4}{*}{ Soil factor } & Mean soil organic matters & SOM & $\mathrm{mg} / \mathrm{g}$ & 1 \\
& Mean soil surface temperature & $\mathrm{SST}$ & ${ }^{\circ} \mathrm{F}$ & 2 \\
& Mean soil temperature & $\mathrm{ST}$ & ${ }^{\circ} \mathrm{F}$ & 2 \\
& Mean 0-5 cm soil moisture & $\mathrm{SM}$ & $\%$ & 2 \\
\hline \multirow{5}{*}{ Air factor } & Mean precipitation & $\mathrm{AP}$ & $\mathrm{mm} / \mathrm{h}$ & 2 \\
& Mean air temperature & $\mathrm{AT}$ & ${ }^{\circ} \mathrm{F}$ & 2 \\
& Mean air humidity & $\mathrm{AH}$ & $\%$ & 2 \\
\hline \multirow{5}{*}{ Anthropogenic } & Mean wind speed & $\mathrm{WS}$ & $\mathrm{m} / \mathrm{s}$ & 2 \\
\hline Factor & Mean PM ${ }_{2.5}$ concentration & $\mathrm{PM} 2.5$ & $\mu \mathrm{g} / \mathrm{m}^{3}$ & 2 \\
& Mean PM 10 concentration & $\mathrm{PM} 10$ & $\mu \mathrm{g} / \mathrm{m}^{3}$ & 2 \\
& Mean vegetation coverage & $\mathrm{VG}$ & $\%$ & 3 \\
\hline
\end{tabular}

1 was referred to that the data were obtained from this experiment.

2 was referred to that the data were obtained from the WorldClim database (http://www.worldclim.org)

3 was referred to that the data were obtained from China annual Vegetation Index (NDVI) spatial distribution data set.

4 was referred to that the data were obtained from China Statistical Yearbook. 


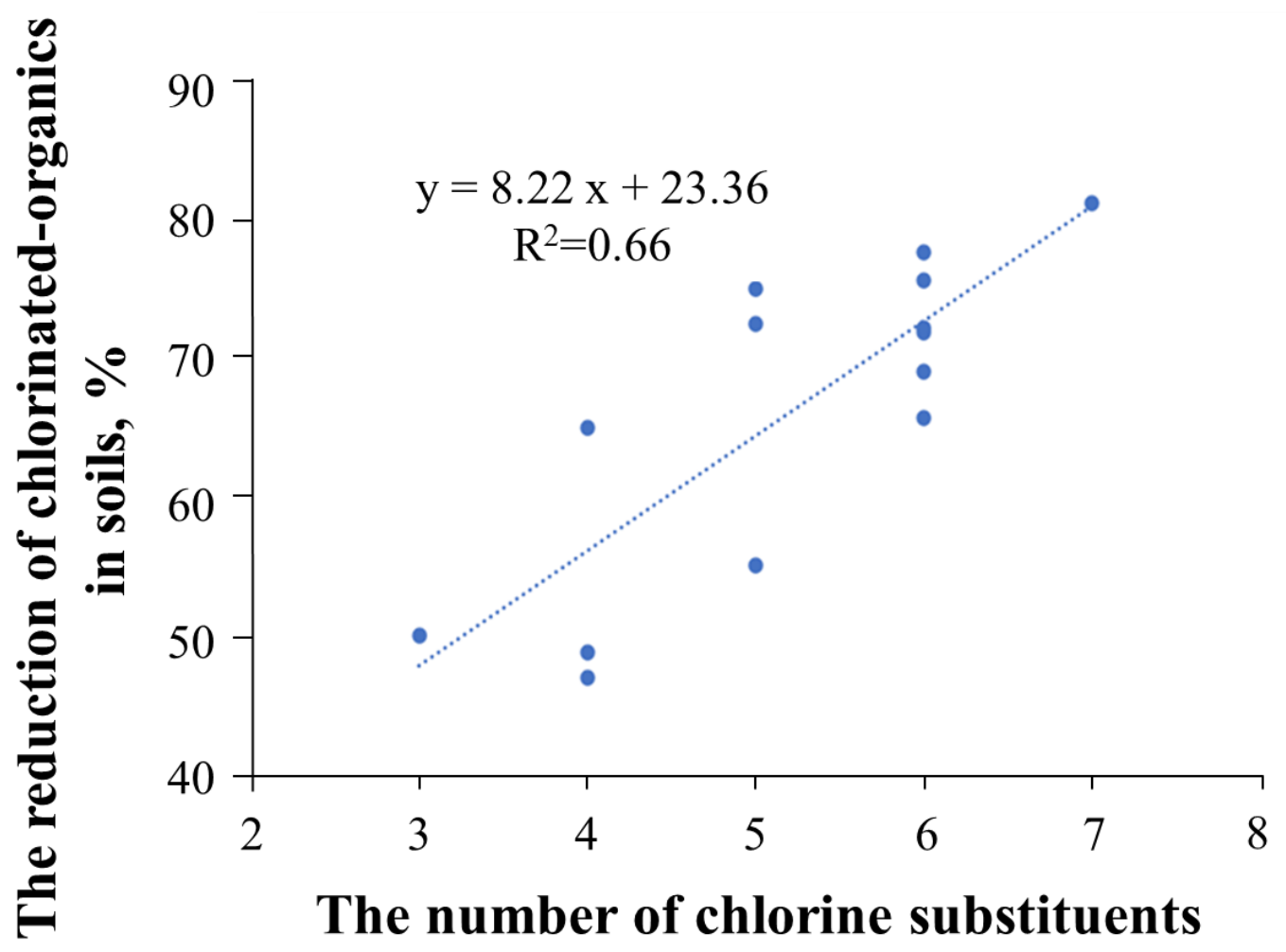

Figure S1. The decrease of the chlorinated-organics in soils after the typhoon as a function of the number of chlorine substituents. 

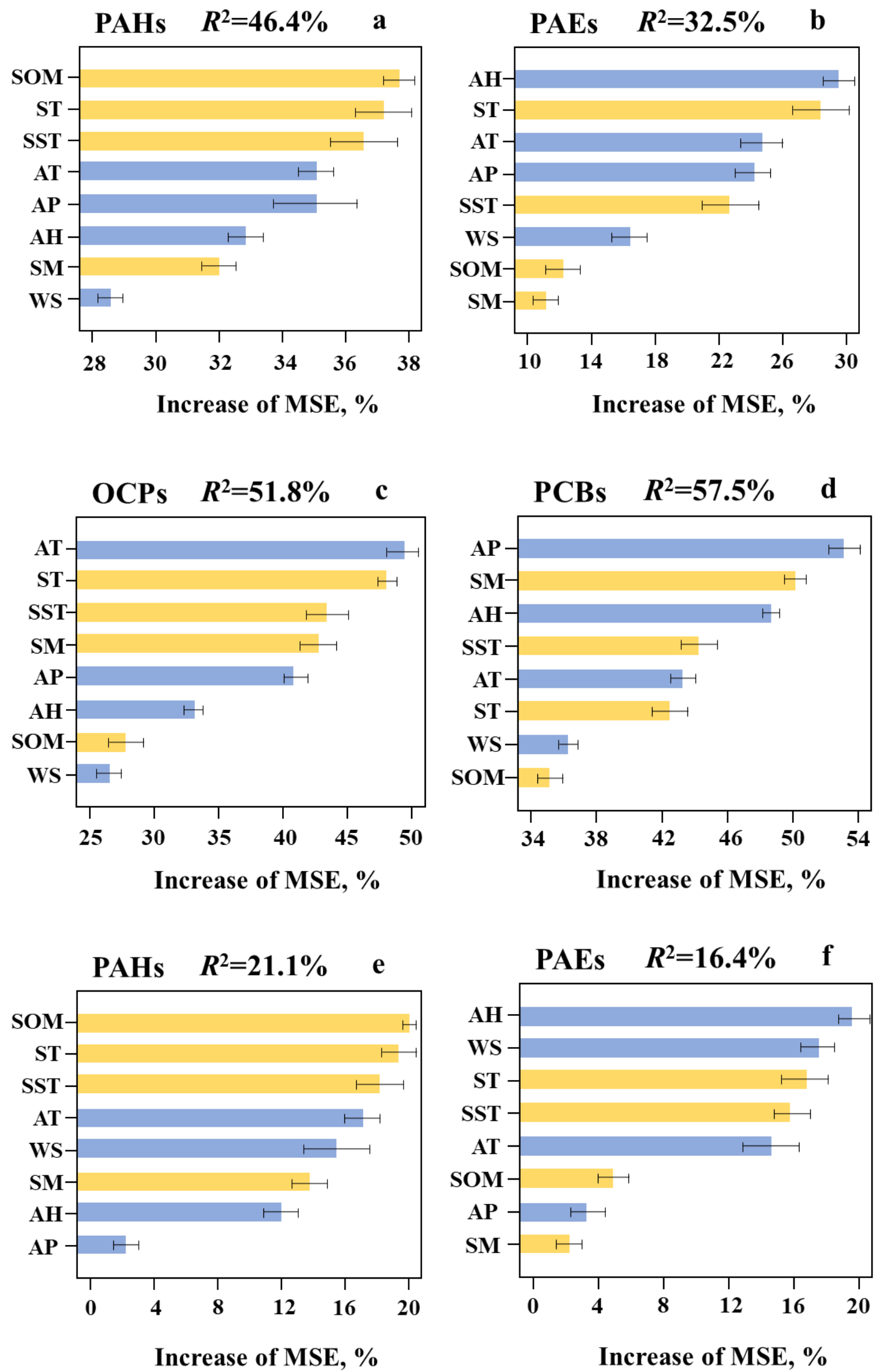

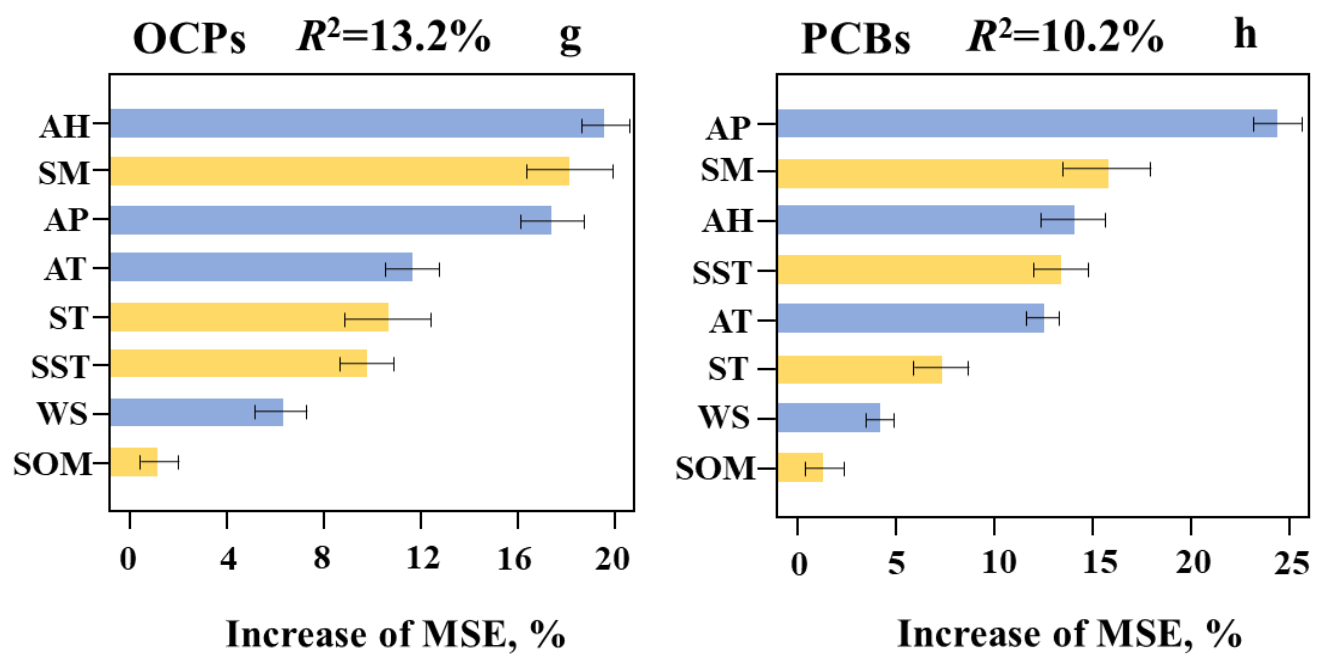

Figure S2. The major drivers of the disturbance of soils organic contaminants in YRD during the typhoon period (a-d) and the sampling period (e-h). The figure illustrates the importance of the top eight significant factors among twelve tested factors (analyzed using Random Forest Model). $\mathrm{R}^{2}$ is the percentage of the explained variance of organic contaminants for eight variables. MSE is mean square error. An increase in the percentage of MSE is equal to the increase in the mean square error. Mean precipitation, AP; Mean air temperature, AT; Mean air humidity, AH; Mean wind speed, WS; Mean soil temperature, ST; Mean soil surface temperature, SST; Mean 0-5 cm soil moisture, SM; Soil organic matter, SOM. 


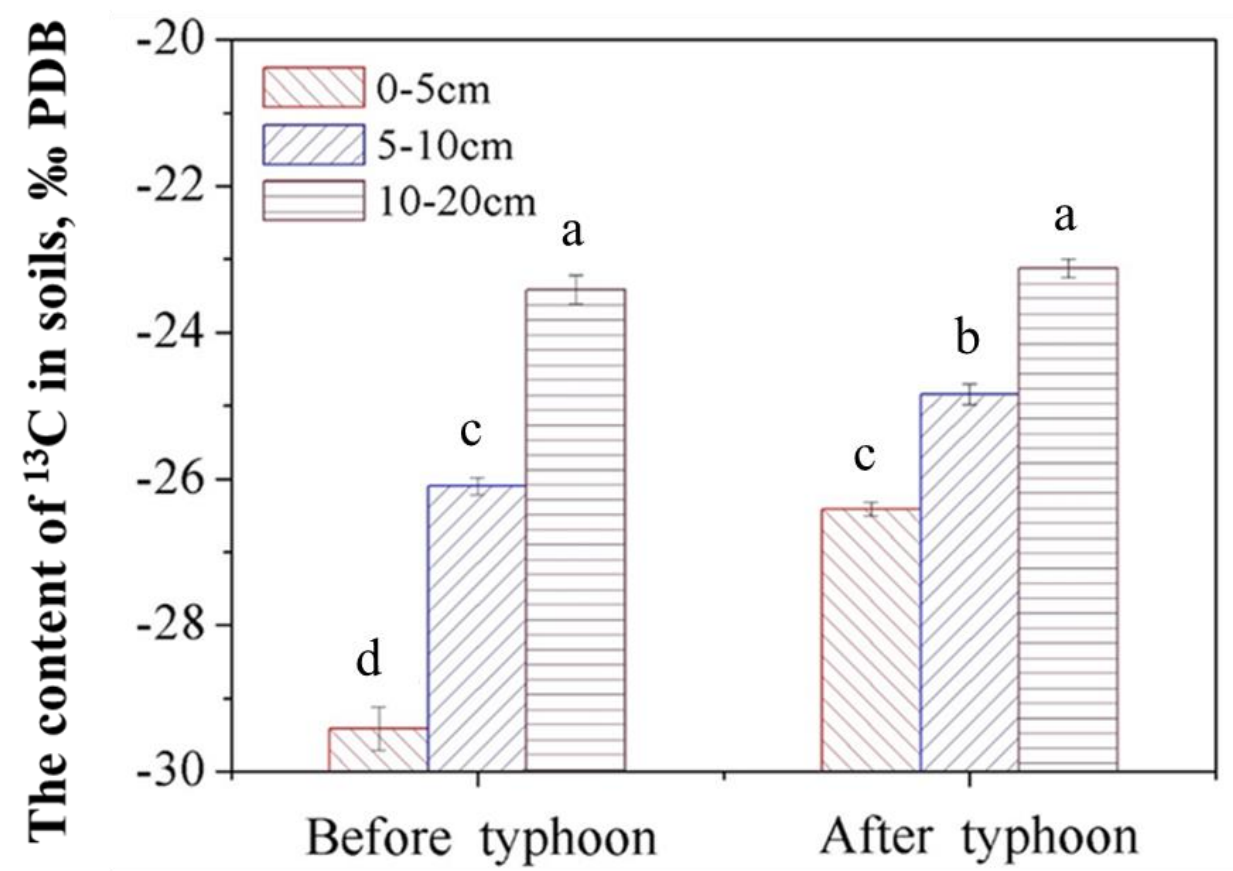

Figure S3. The vertical distribution of ${ }^{13} \mathrm{C}$ in agricultural soils from the Yangtze

River Delta before and after the typhoon Lekima. The soil profiles were divided into 0-5 cm, 5-10 cm and 10-20 cm. Different letters indicate significant differences among the treatments by LSD post hoc comparison tests at $p<0.05$. The difference is obtained from pairwise comparison. 

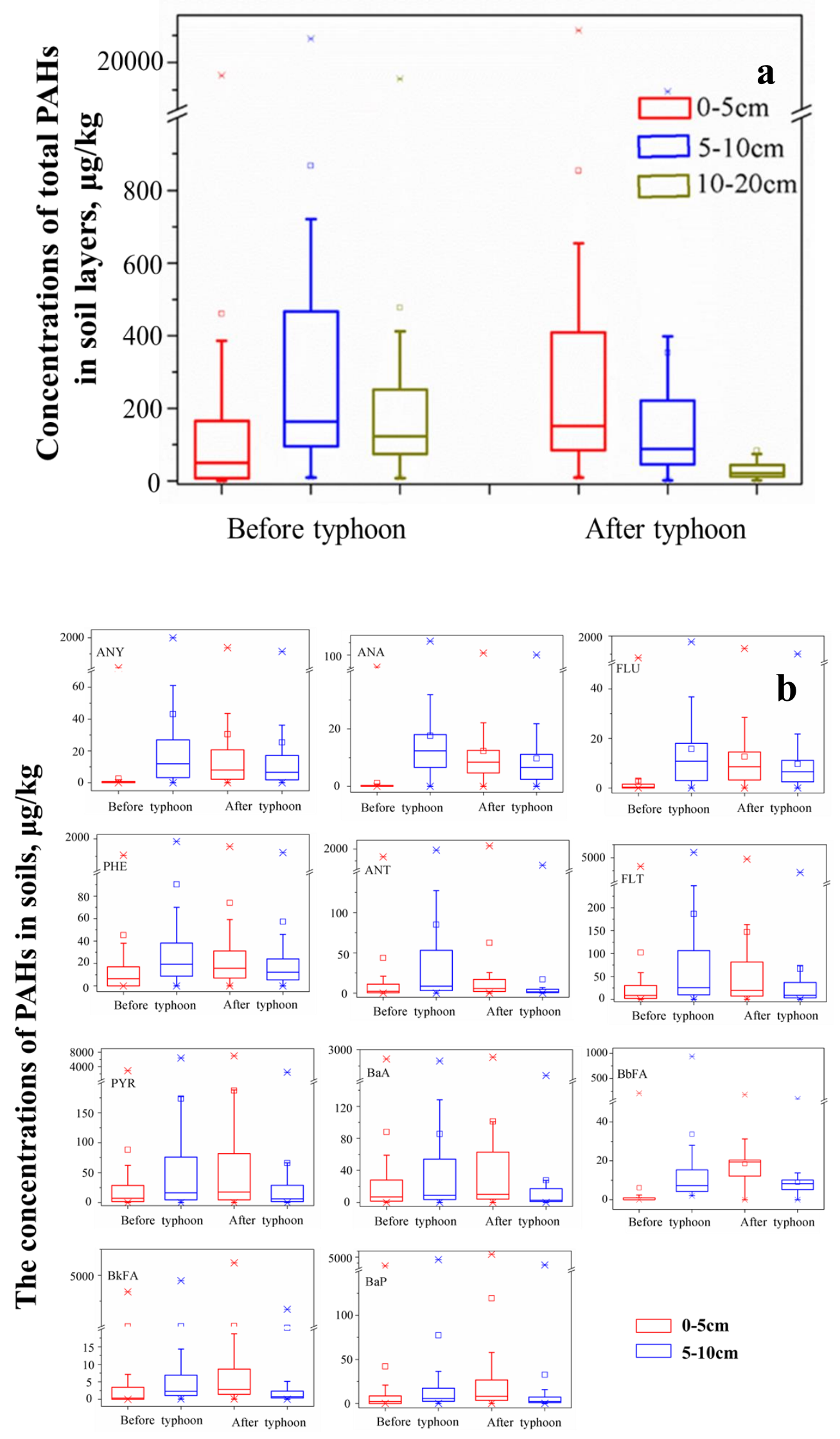
Figure S4. The vertical distribution of total PAHs (a) and PAH monomers (b) in agricultural soils from the Yangtze River Delta before and after the typhoon Lekima. 


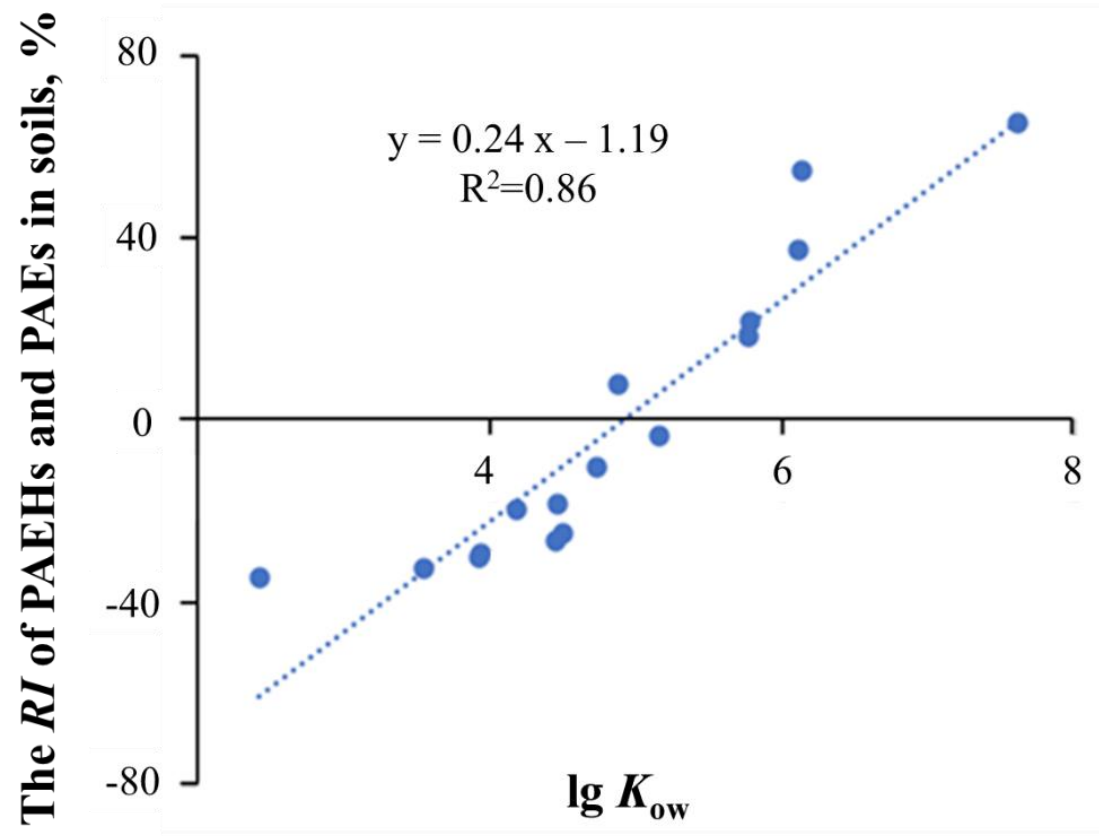

Figure S5. The relationship between $R I$ and $\lg \boldsymbol{K}_{\text {ow. }} R I$ is the relative increment which indicates the increased concentrations of organic contaminants in the $0-5 \mathrm{~cm}$ soils after the typhoon relatively to that in the $5-10 \mathrm{~cm}$ soils before the typhoon. 


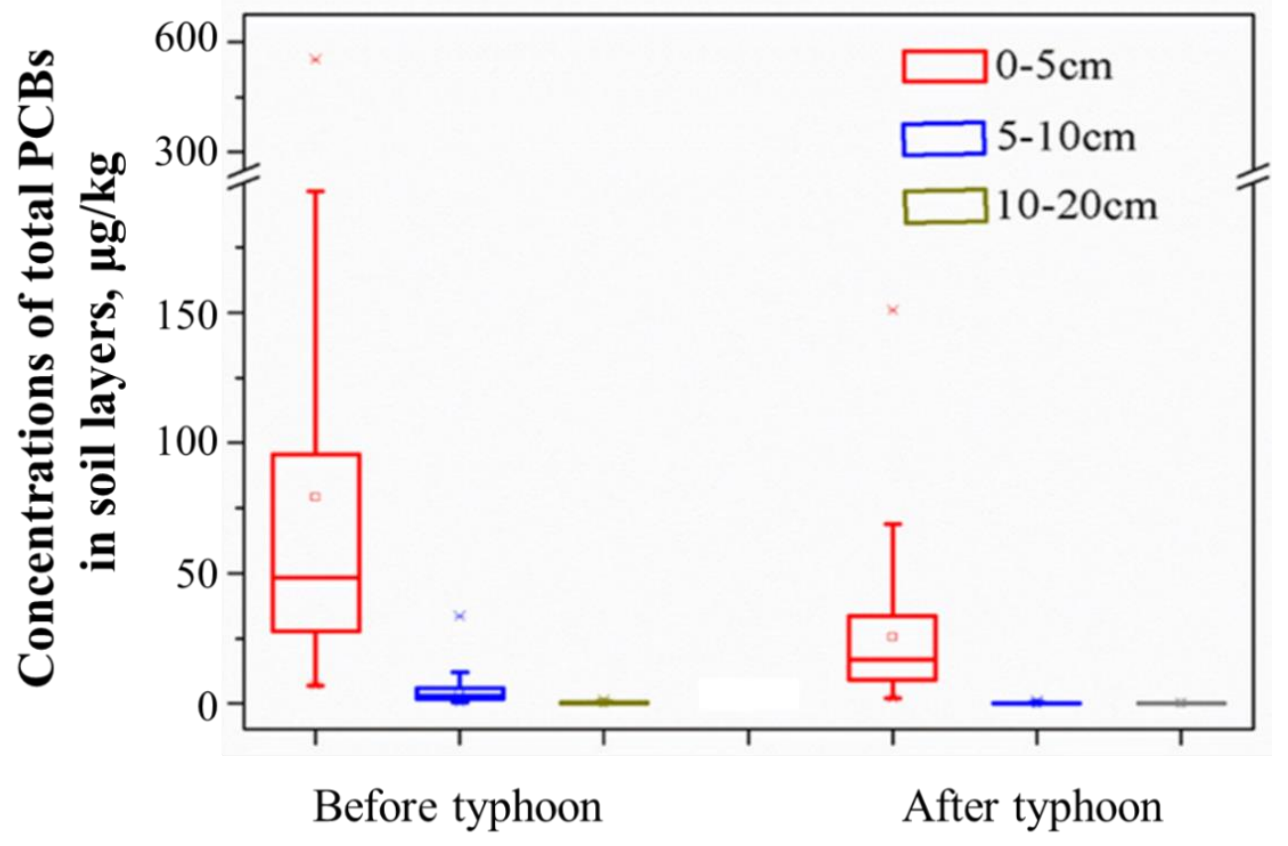

Figure S6. The vertical distribution of total PCBs in agricultural soil profiles from the Yangtze River Delta before and after the typhoon.

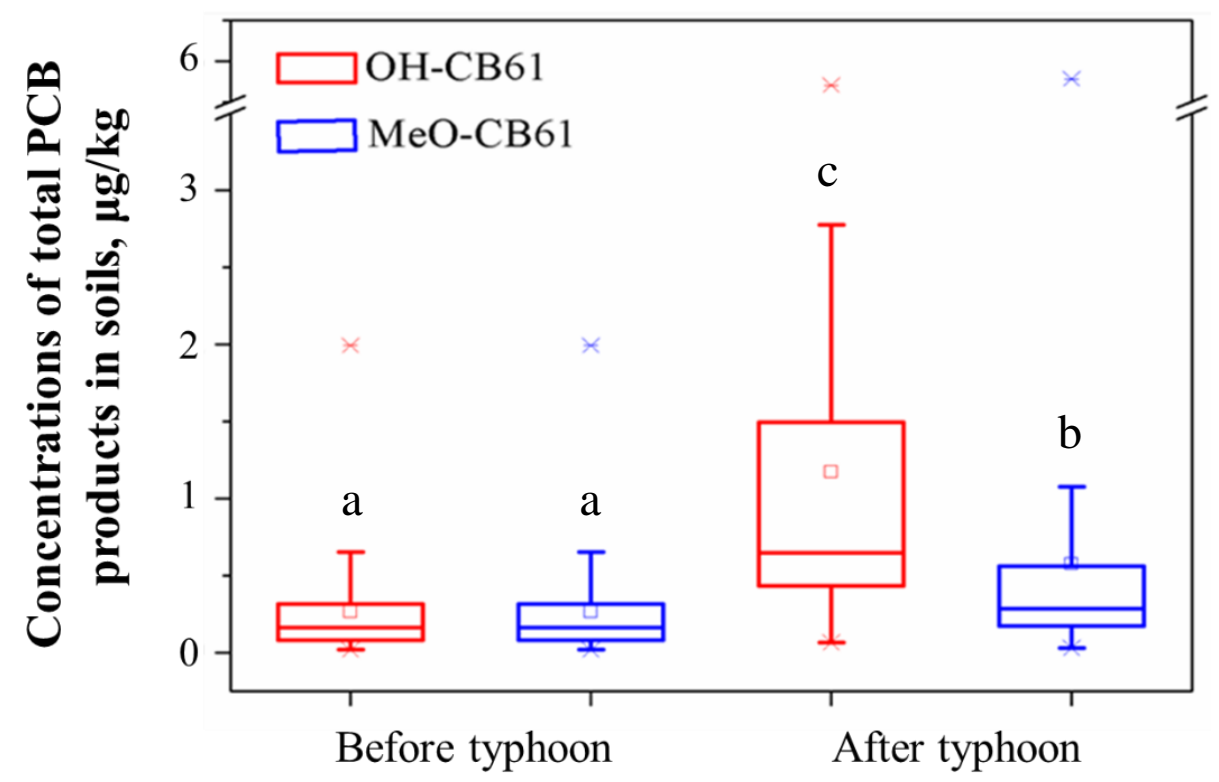

Figure S7. The transformation products of PCBs in 0-20 cm soils from the Yangtze

River Delta before and after the typhoon. Different letters indicate significant 
differences among the treatments by LSD post hoc comparison tests at $p<0.05$. The difference is obtained from pairwise comparison.

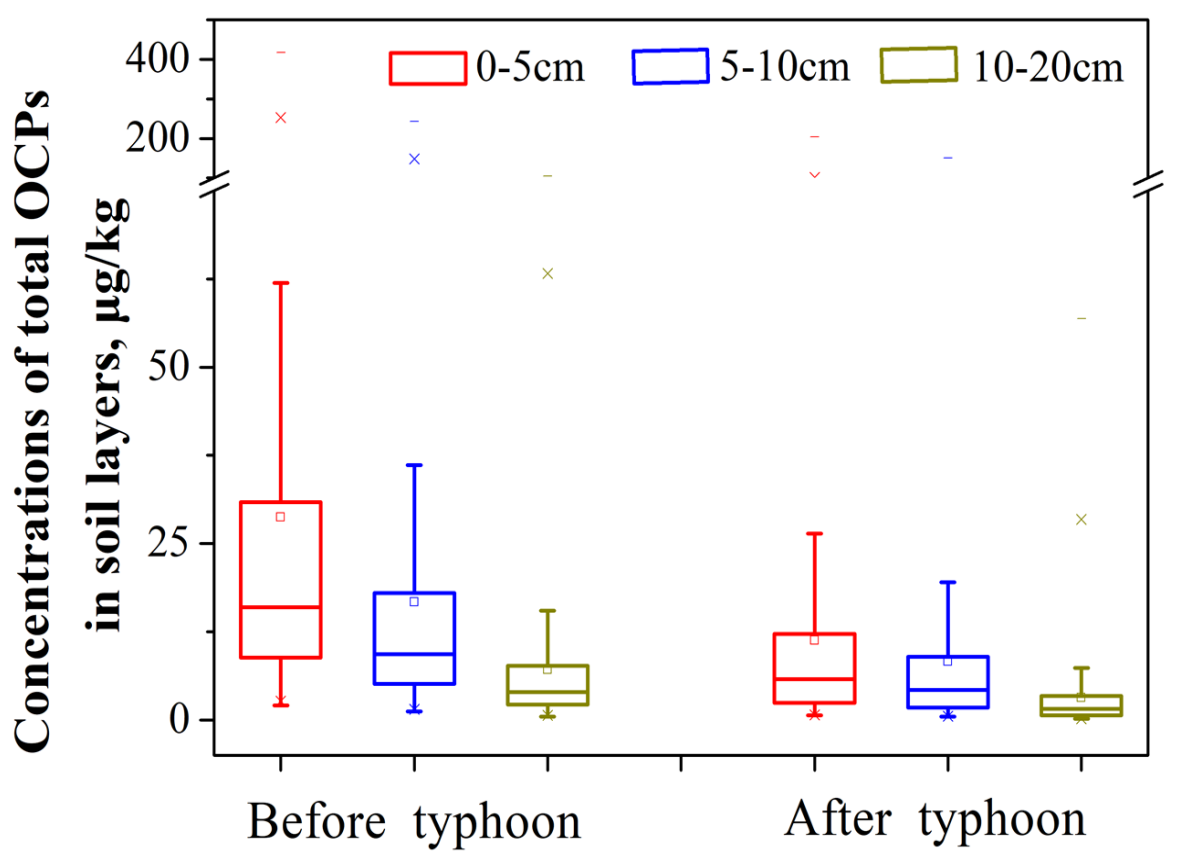

Figure S8. The vertical distribution of total OCPs in agricultural soil profiles from the Yangtze River Delta before and after the typhoon. 

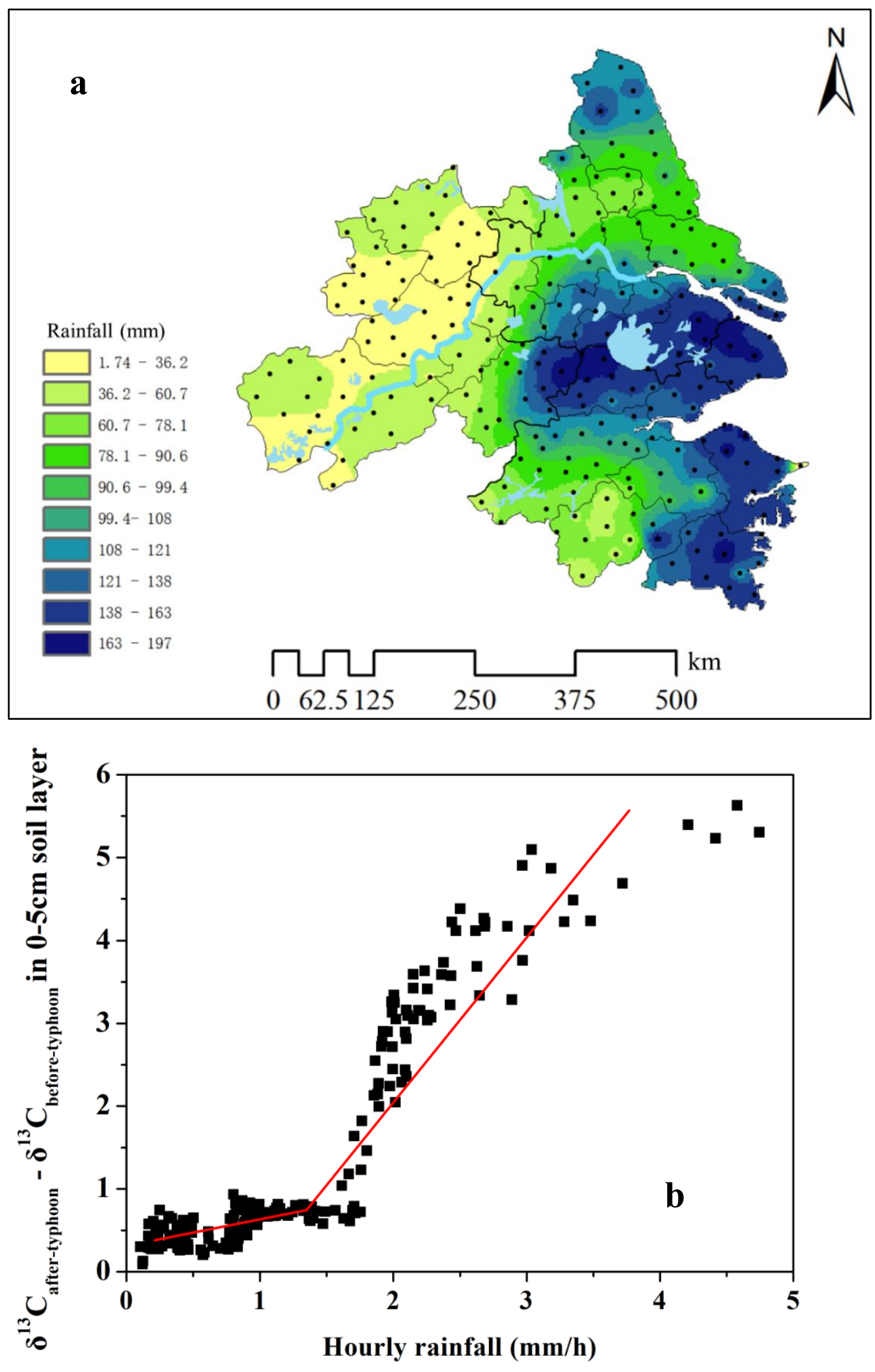


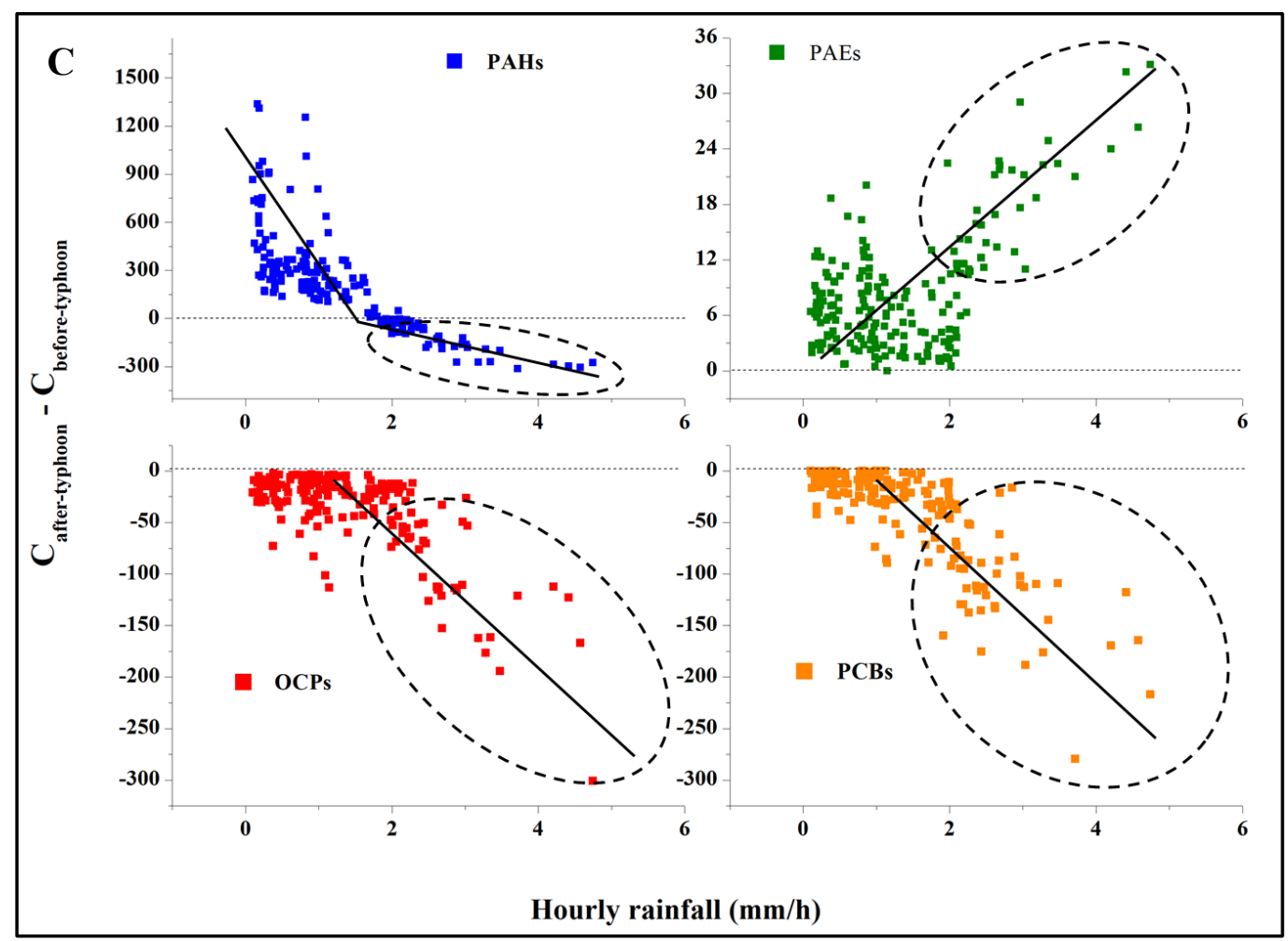

Figure S9. The distribution of total rainfalls in the YRD during the typhoon. (a)

The effects of hourly rainfalls on the soil erosion during the typhoon. (b) $\delta^{13} \mathrm{C}$ was referred to the content of ${ }^{13} \mathrm{C}$ isotopic composition. The effects of hourly rainfalls on the soil organic contamination during the typhoon. (c) $\mathrm{C}$ was referred to the concentrations of organic contaminants in soils. The dotted circle represented the main area of typhoon track. The $30 \mathrm{~km}$ diameter of the typhoon eye was considered as the main area of typhoon track. 


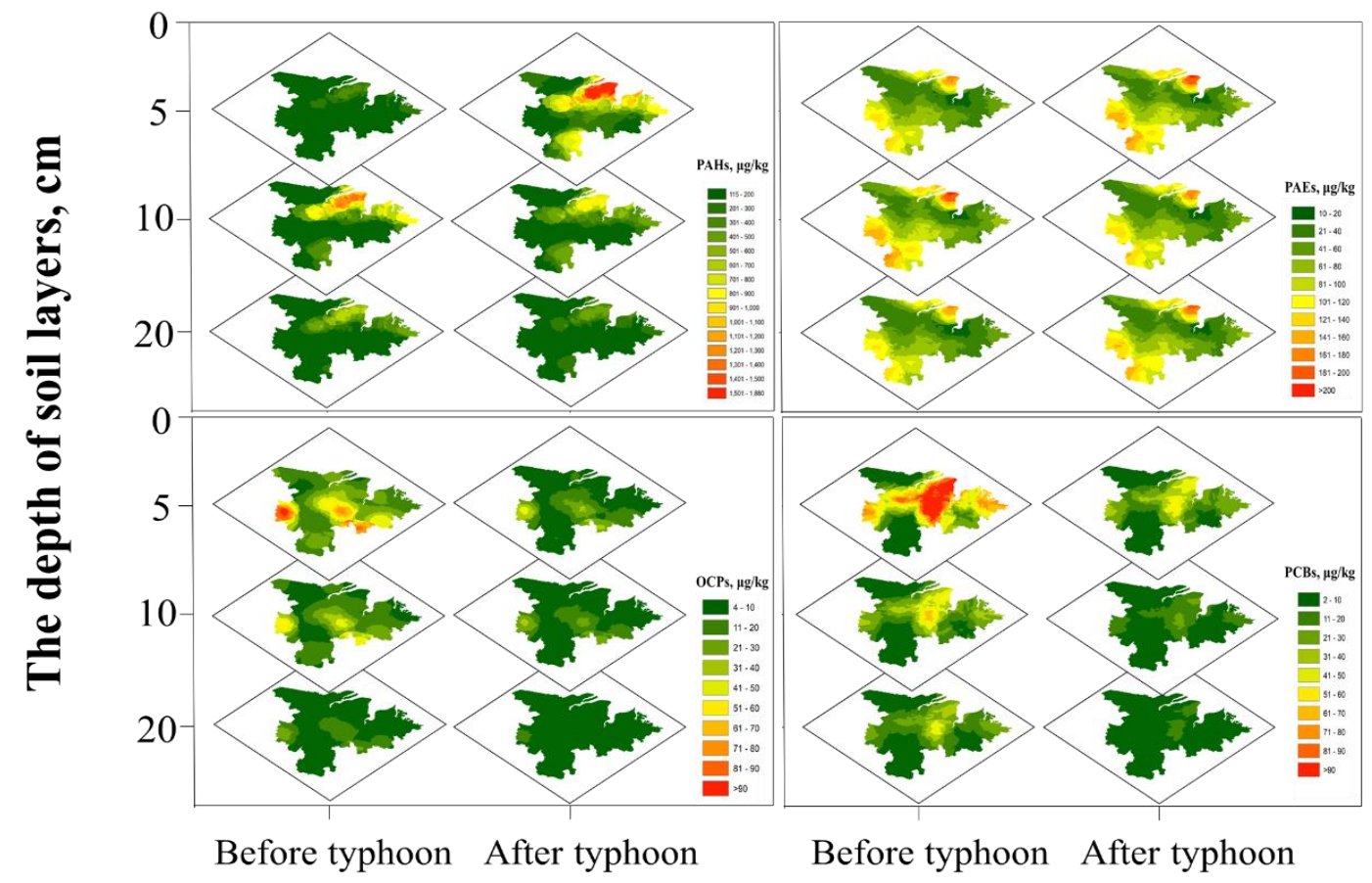

Figure S10. The vertical spatial distribution of organic contaminants in 0-5 cm, 5-

$10 \mathrm{~cm}$ and $10-20 \mathrm{~cm}$ soil layers from the Yangtze River Delta during the typhoon. 